\title{
Effect of the Flowability of Dust on Collection Performance of Repeatedly Dislodged Filter Cloth
}

\author{
Mitsuaki Hirota, Yoshio Shimizu* and Toshio Oshima \\ Dept. of Chem. Eng., Himeji Inst. of Tech., Himeji 671-22
}

Key Words: Dust Collection, Powder, Dislodging, Flowability, Bag Filter

The effect of the flowability of dust on the collection performance of filter cloth was studied by using three kinds of dusts of different flowabilities. In the case of dislodging the filter cloth, the amount of dust remaining on the dislodged filter cloth was considerably affected by the flowability of the dust. For dust of low flowability, pressure drop across the filter cloth and collection efficiency were higher than for dust of high flowability when the same amount of dust remained on the filter cloth.

* DAIFUKU CO., LTD.

\section{対称および非対称加熱垂直平行平板間自然対流熱伝達 ${ }^{\dagger}$ 半沢 保・石原秀樹・関口邦明*・藤井隆彦 ${ }^{* *}$ 鈴木康夫 ${ }^{* * *}$ ・加藤邦夫 \\ 群馬大学工学部 化学工学科}

\section{緒 言}

近年, 電子工学の発達に伴い, 電子回路の高密度化, 小型化が盛んに進められている。乙の電子回路は熱の影 響を非常に受けやすく, それゆえ，系内に発生する熱の除 去を正確に予測するてとが非常に重要な問題になっている. これら電子回路はエポキシ樹脂板等に取付けられて電子 回路板となり, 電子器機内に扔いて一定間隔で垂直に設 置される。乙の場合, 系内では浮力による自然対流が生 じ, 回路板からの熱の除去が容易之なる. ゆえに, 電子回 路板内での熱移動や温度分布解析をするには, 垂直平行 平板間の熱伝達係数を知ることが必要である.

ところで, 自然対流を伴った垂直平行平板間の流動特 性や熱移動に関しては, 実験的にも理論的にあ多数の研 究が報告されている, 3 8,10 20,22,23). しかし，てれらの研

\footnotetext{
†1986年 2 月 6 日受理；化学工学協会第 48 年会 (京都, 1983 年 4 月），同第 50 年会 (横浜, 1985年 3 月)にて 一部発表

\# $\overline{1} 376$ 桐生市天神町 1-5-1

* 日立コンデンサ(侏)

** 倉敷化工(侏)

*** 日立プロセスコンピュータエンジニアリング姝
}

究の多くは, 加熱板と流体との温度差が比較的小さく, 運動量や熱の移動現象が緩慢な場合を扱っている $(G r<$ $\left.10^{4}\right)$. しかるに, 電子器機内では, 電子回路板之周囲流 体との間に比較的大きな温度差が存在し， $G r$ 数も時に は $10^{8}$ にあ達する。

本研究では, 電子器機内の熱移動現象を定量的に解明 するための基礎資料を得ることを目的として，垂直平行 な 2 平板が対称に，または非対称に一様温度で加熱され る場合について, 高 $G r$ 数下で平板からの熱伝達係数に 及ぼす諸因子の影響を調べた。

\section{1. 実験装置および実験方法}

装置の概要を Fig. 1 亿示す. 加熱板は両面にアルミ板 を取付けた枠内に, 発熱体としてカンタル線を上, 中, 下の 3 箇所に別々に入れ，供給熱量を各々調整できるよ うにした。板の大きさは 30 (高さ) $\times 45$ (幅) $\mathrm{cm}^{2}, 60$ $\times 45 \mathrm{~cm}^{2}$ の 2 種類で，各々の加熱面温度は 8 本の銅・ コ ンスタンタン熱電対を加熱面に埋込んで測定したが，そ の配置は測定面に 5 点 (図B ), 加熱面温度の対称性を 調べるために, 測定面の背中合わせの面に 3 点取付けた. 系内流体温度は, $0.25 \mathrm{~mm} \phi$ のシース型銅・コンスタ ンタン熱電対を, 装置上部より系内に挿入して測定した。 

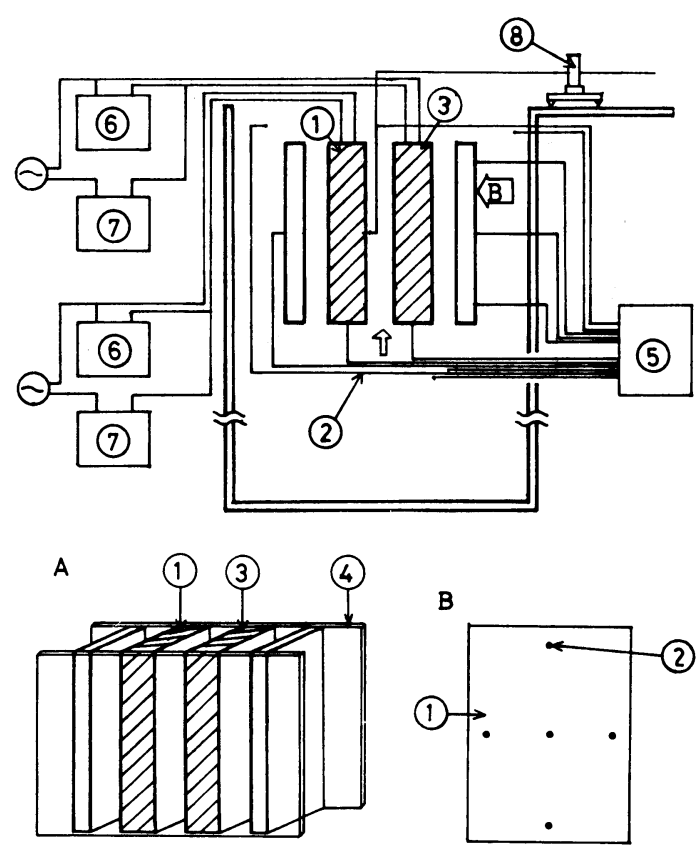

Fig. 1 Experimental apparatus, (1) Heated plate, (2) Thermocouples, (3) Opposite plate, (4) Side plate, (5) Recorder, (6) Voltmeter, (7) Ammeter, (8) Slider

実験方法は, 加熱面温度を各々の設定温度において一 定にし，系内各壁温を記録しながら，装置上部から㨂入 した熱電対をスライダーで移動させて, 垂直平行平板間 のガスの局所温度を測定した，操作条件は，加熱面温度 が $323,373,423 \mathrm{~K}$, 平板間距離は $0.75,1.0,2.0,3.0$ お

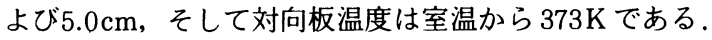
なお，系内ガス温度分布を調べるため，加熱面下部から 垂直方向に 5〜 10cm おきに, また, 水平方向に加熱面 近傍では $0.2 \mathrm{~cm}$ おきに，他の部分では $0.5 \sim 1.0 \mathrm{~cm}$ おき にガス温度を測定した，さらに，加熱平板に供給した電 力もあわせて測定した。

\section{2. 実験結果および熱伝逴係数の相関}

得られた実験結果の一部を以下に示す。

Fig. 2 は加熱面温度を $373 \mathrm{~K}$ で一定にした場合の, 各 平行平板間距離におりる系内温度分布の実測値を示すが, こてでは一例として加熱面高さ $H=60 \mathrm{~cm}$, 対向板温度 $t_{W}$ を非加熱扰よび373K の場合で，垂直方向距離 $y$ をパラ メータとして示す．図は横軸が平板間距離 $D$ を, 縦軸に 無次元温度をとるが，図より，D=3cm 以上の場合には， 系内全域において, 加熱面近傍でのみ急激な温度勾配が あるが， $D=1 \mathrm{~cm}$ ではこの傾向は，加熱面下端近傍での み見られることがわかる。また，Dが小さいほど，そし て $t_{W}$ が高いほど，yに対する温度上昇が見られる，以
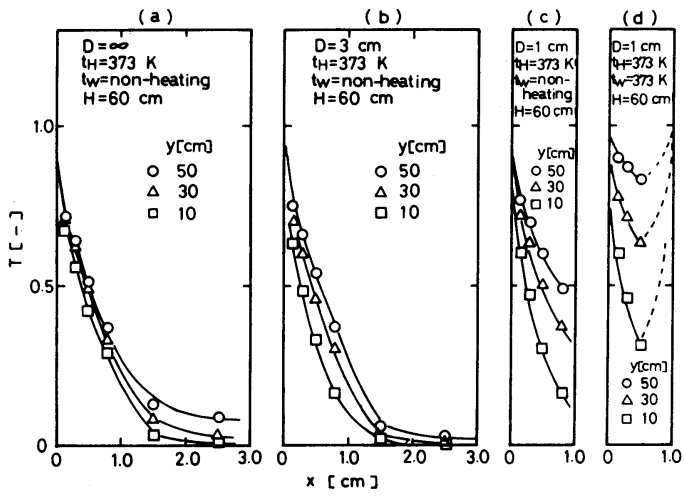

Fig. 2 Effect of plate spacing on the crosssectional temperature distributions

上の系内温度分布の傾向は, $H=30 \mathrm{~cm}$ の系における測 定でも同様にみられた。なお, これらの垂直方向距離 $y$ に対する温度分布の発達の形状は, 宮武, 藤井の同様な 系に抢ける基礎式の数值解析結果とも, 大略同じであっ $た^{25 !}$.

電子器機内に充媜された, 電子回路板表面からの熱移 動に対する基礎資料として, 垂直平行平板加熱面におけ る局所熱伝達係数 $h$ が必要となる。乙てでは $h$ を任意の 垂直方向位置での温度勾配と, そての $t_{H}$ と入口ガス温 度 $t_{A}$ との差を使用し, 次式により求めた。

$$
h=-\frac{\lambda\left(\frac{\partial t}{\partial x}\right)_{x=0}}{t_{H}-t_{A}}
$$

なお, 本研究では温度勾配 $(\partial t / \partial x)_{x=0}$ として, 加熱面 と加熱面最寄りの測定点一点との温度勾配を使用した。

また，垂直平行平板間の平均 $N u$ 数に影響を及ぼす因 子について検討を行ったが, 平均 $N u$ 数は次の定義に基 づいて得たあのを使用した。

$$
\bar{h}=\frac{1}{H} \int_{0}^{H} h d y
$$

$$
\overline{N u}=\frac{D \bar{h}}{\lambda}
$$

さらに, 供給電力に基づく熱収支より次式が得られる.

$$
Q=\bar{h} A\left(t_{H}-t_{A}\right)
$$

Eqs.(2)，(3)より求めた $\overline{N u}$ と, Eq.(4)より求めた $\overline{N u}$ とは $\pm 5 \%$ 以内で一致した。

Fig. 3 は対向板が加熱扔よび非加熱である場合におけ る $h$ の分布を, 一例として $H=60 \mathrm{~cm}, t_{H}=373 \mathrm{~K}$ につい て，Dをパラメータとして示す. 図(a)より，対向板が非 加熱の場合, $D$ が大きいほど $h$ は $y$ の増加に従って一定 值に近づくことがわかる．他方，対向板が加熱されてい 

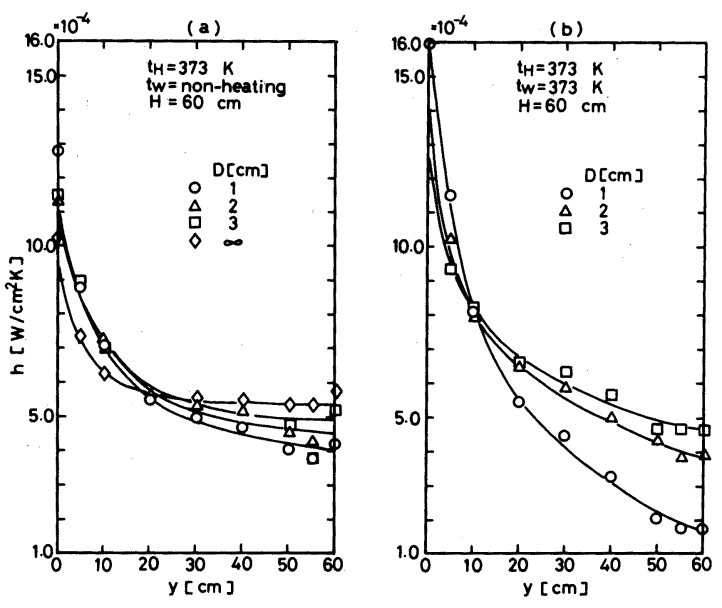

Fig. 3 Effect of plate spacing on the local heat transfer coefficient

る場合は, 図(b)より，hはDによって大きく影響を受け， かつDの小さい場合ほど, $y$ の増加と共に $h$ は著しく小 さくなることがわかる.

次に, 垂直平行平板間の平均 $N u$ 数に対して, 影響を 及ぼす因子として $G r$ 数, $H / D$, および $t_{W}$ に対する無次 元温度 $\theta$ を取り, 乙れら因子と平均 $N u$ 数との関係を求 めた。なお，ててでは対向壁が非加熱で, 対向壁面温度 が一様にならない場合の $\theta$ は, 壁面での実測值の平均に より求めた.

Fig. 4 は $\overline{N u}$ に対する $(1+\theta)$ の関係を, 一例として $H=60 \mathrm{~cm}, H / D=20[-]$ の場合について, $G r$ 数をパラ メータとして示す. 図より, $\overline{N u}$ は $(1+\theta)$ の增加と共 に減少し, $\overline{\mathrm{Nu}}$ は $(1+\theta)$ の-0.12 乗に比例するてとが わかる。

また, $\overline{N u}$ に対する $G r$ 数および $H / D$ の関係も調べ, $\overline{\mathrm{Nu}}$ は $\mathrm{Gr}$ 数の 0.25 乗に, そして $H / D$ の-0.26乗にそれ ぞれ比例することがわかった。

以上の結果に基づき, 全測定值について $\overline{N u}$ 之諸因子 との関係を示したのが Fig. 5 である. これより, 垂直平 行平板間での平均 $N u$ 数之諸因子との関係に対して, 本 実験での操作条件の範囲において次式を得た。

$$
\overline{N u}=0.75(1+\theta)^{-0.12} G r^{0.25}(H / D)^{-0.26}
$$

図より, 対向壁面温度が一様にならない場合, その平均 值を使用して $\theta$ を定めてあ, 相関式とよく一致するてと がわかる，また，図中には類似の系に扔ける他の研究者 の実測値および数值解析結果も記したが, こてで, 対向 壁が断熱壁の時は, $H / D$ が小さくなると $\theta$ は 1.0 亿近づ くので, 乙の場合 $\theta=1.0$ とみなして図中に示した. 図 より, 相関は大略良好であると思われる。なお, 宮武,

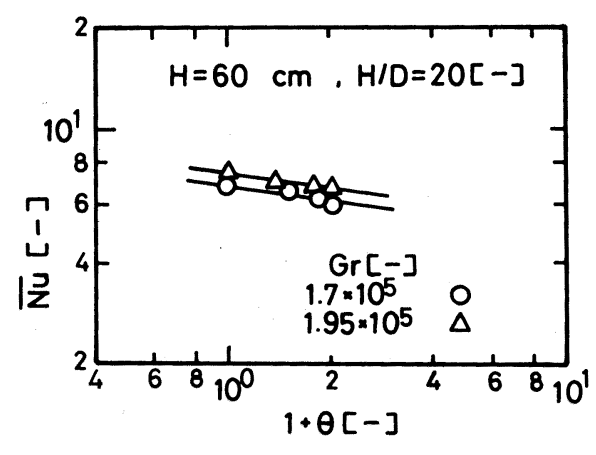

Fig. 4 Relation between experimental $\overline{\mathrm{Nu}}$ and $(1+\theta)$

藤井は本研究と同様の系において, $(D / H) G r$ が大きい 場合の $P r=0.7$ におりる漸近式に対して, 対向壁が断熱 の場合と，相異なる温度をあつ場合のそれぞれについて 次式を与えている ${ }^{15,17}$.

$$
\begin{aligned}
& \overline{N u}=0.561\left(\frac{D}{H} G r\right)^{0.25} \\
& \overline{N u}=0.53\left\{1+0.165(1-\theta)^{0.36}\right\}\left(\frac{D}{H} G r\right)^{0.25}
\end{aligned}
$$

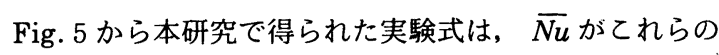
式より若干大きくなる傾向を示した。

ここで, Eq.(5)の適用範囲は $\theta=0 \sim 0.99[-], D=1 \mathrm{~cm}$ 以上, $H / D=6 \sim 60[-]$, そして $G r=10^{3} \sim 10^{7}[-]$ であ る.

\section{3. 考察}

Fig. 6 は Eq.(2)によって得た平均熱伝達係数 $\bar{h}$ に対し $\tau$, 加熱面温度 $t_{H}$ と対向板温度 $t_{W}$ との差 $\left(t_{H}-t_{W}\right)$ の影 響を, 一例として $H=60 \mathrm{~cm}, t_{H}=373 \mathrm{~K}$ の場合について, 平板間距離 $D$ をパラメータとして示す. 図より $D=1 \mathrm{~cm}$ 以上の場合, $\left(t_{H}-t_{W}\right)$ が小さくなると共に $\bar{h}$ はわずかに 増大するが, $D=0.5 \mathrm{~cm}$ ではこの傾向が逆転し, $\left(t_{H}-t_{W}\right)$ の減少に従って

てのてとは，Dが $1 \mathrm{~cm}$ 以下になると，Dの隇少によ り系内での対流の発達が極度に抑制されるためと推察さ れるが，乙こで垂直平行平板間の自然対流によるガス流 速について考える。いま, 系を細長い長方形断面のダク 卜と考えると, 系内上昇速度は次式により得られると思 われる。

$$
\begin{aligned}
& \Delta p=\left(\rho_{A}-\bar{\rho}\right) g H \\
& \Delta p=\frac{2 f \rho H \bar{v}^{2}}{D_{e}}
\end{aligned}
$$

Eqs.(6), (7)において $f=16 / R e$ とし, また他の因子につ いては本実験の実測值を使用して, 系内上昇速度 するDの影響について考察すると，Dの増加と共に系内 


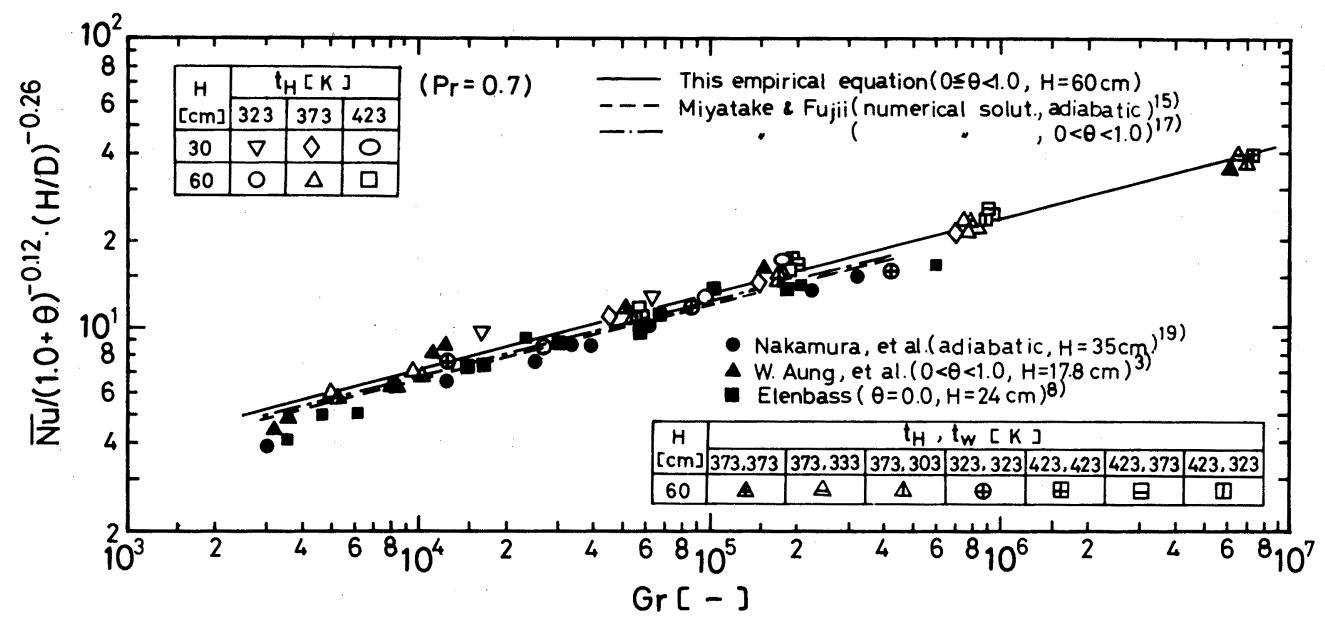

Fig. 5 Relation between $\overline{N u}(1+\theta)^{0.12}(H / D)^{0.26}$ and $G r$

温度は低下し, $\left(\rho_{A}-\bar{\rho}\right)$ が小さくなって, $\bar{v}$ は緩やかな 増加を示す。逆に, $D=1.0 \mathrm{~cm}$ 以下になると, $\bar{v} は$ 急速 に減少すると推察される。結局, 本装置での系内の移 動現象は, 大略 $D=1 \mathrm{~cm}$ 前後を境にして, 完全に異なっ た性状を示すと思われる，Bar-Cohen らは垂直平行平板 について, 自然対流による冷却のための最適間隔に関し て報告している゙)。乙の文献に打ける最適値の式によると， 本研究での最適間隔は, 本実験条件下で約 $D=0.9 \mathrm{~cm}$ と なる，ところで，乙の最適間隔は比較的大きい熱移動速 度での最小平板間隔ということで, Fig. 6 の $\bar{h}$ の特異点 に関連すると考えられるから，ての図で $D=1 \mathrm{~cm}$ が先の 最適値 $D=0.9 \mathrm{~cm}$ と大略合致するととは, 本実測值と系 内速度に対する考察とが大略妥当であることを示すと思 われる。

単一垂直平板からの熱伝達は, 平行平板において, 平 板間距離が充分大きい場合のそれに相当すると言える. そてで, Eq.(5)は単一平板にも適応できるよう配慮した。 一般に，等温の単一垂直平面からの自然対流に上る熱移 動は次式で示される ${ }^{2,9,21,24)}$.

$$
\overline{\mathrm{Nu}}=\mathrm{CGr^{n }}
$$

こてで, $C=0.3 \sim 0.7, n=1 / 5 \sim 1 / 4$ である. Eq.(5)を等 温単一平板に適応させると次式となる。

$$
\overline{N u}=0.69 G^{0.25}
$$

Eqs. ${ }^{(8)}$ と(9)の一致は大変良好と思われる.

\section{結 言}

一様温度の 2 枚の垂直平板間の自然対流熱伝達につい て, 非対称加熱加ら対称加熱までの広範囲にわたって, 比 較的高 $G r$ 数のもとで実験を行い, 以下の結果を得た。

1) 加熱面での局所熱伝達係数 $h$ は, 対向板が非加熱 の場合，Dが大きいほど加熱面に沿って一定になるが, 対向板が加熱されている場合は，Dの影響を受けやすい．

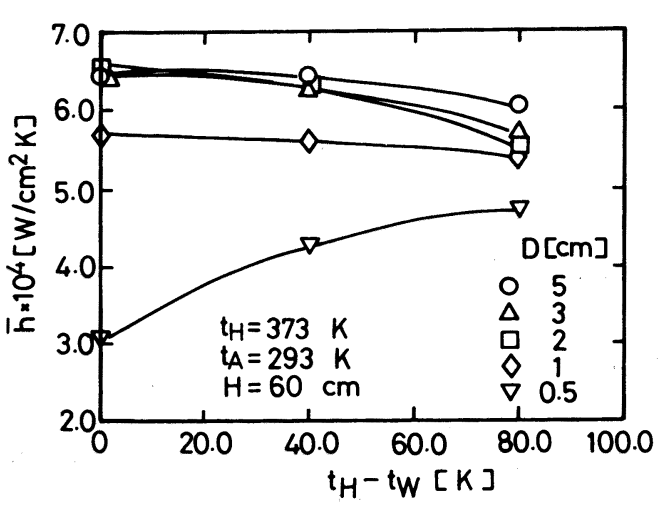

Fig. 6 Effect of temperature difference between heating plate and opposite plate on the average heat transfer coefficient

2) 平均熱伝達係数に対する実験式として Eq.(5)を得 た.

\section{Nomenclature}

$$
\begin{aligned}
& A=\text { surface area of heating plate } \\
& C_{p}=\text { heat capacity at constant pressure } \\
& D=\text { plate spacing } \\
& D_{e}=\text { hydraulic diameter } \\
& f \quad=\text { friction factor } \\
& G r=\text { Grashof number }\left(=g \beta D^{3}\left(t_{H}-t_{A}\right) / \nu^{2}\right) \\
& g \quad=\text { gravitational acceleration } \\
& H=\text { plate height } \\
& h \quad=\text { local heat transfer coefficient } \\
& \bar{h} \quad=\text { average heat transfer coefficient } \\
& N u=\text { Nusselt number }(=h D / \lambda) \\
& P r=\text { Prandtl number }\left(=C_{p} \mu / \lambda\right) \\
& Q \quad=\text { heat duty to heating plate }
\end{aligned}
$$

$\left[\mathrm{cm} / \mathrm{s}^{2}\right]$

$\left[\mathrm{W} / \mathrm{cm}^{2} \cdot \mathrm{K}\right]$ 
$T=$ dimensionless temperature

\begin{tabular}{|c|c|c|}
\hline & $\left(=\left(t-t_{A}\right) /\left(t_{H}-t_{A}\right)\right)$ & {$[-]$} \\
\hline$t$ & $=$ temperature & {$[\mathrm{K}]$} \\
\hline$v$ & $=$ velocity in axial direction & {$[\mathrm{cm} / \mathrm{s}]$} \\
\hline$x$ & $=$ cross-sectional coordinate & {$[\mathrm{cm}]$} \\
\hline$y$ & $=$ axial coordinate & {$[\mathrm{cm}]$} \\
\hline$\beta$ & $=$ volumetric coefficient of expansion & {$\left[\mathrm{K}^{-1}\right]$} \\
\hline$\Delta p$ & $=$ Pressure drop & {$\left[\mathrm{g} / \mathrm{cm} \cdot \mathrm{s}^{2}\right]$} \\
\hline$\theta$ & $\begin{aligned}= & \text { dimensionless temperature of opposit } \\
& \text { plate }\left(=\left(t_{H}-t_{W}\right) /\left(t_{H}-t_{A}\right)\right)\end{aligned}$ & te $[-]$ \\
\hline$\lambda$ & $=$ thermal conductivity & {$[\mathrm{W} / \mathrm{cm} \cdot \mathrm{K}]$} \\
\hline$\mu$ & $=$ viscosity & {$[\mathrm{g} / \mathrm{cm} \cdot \mathrm{s}]$} \\
\hline$\nu$ & $=$ kinematic viscosity & {$\left[\mathrm{cm}^{2} / \mathrm{s}\right]$} \\
\hline$\rho$ & $=$ density & {$\left[\mathrm{g} / \mathrm{cm}^{3}\right]$} \\
\hline \multicolumn{3}{|c|}{$<$ Subscripts $>$} \\
\hline$A$ & $=$ inlet zone & \\
\hline$H$ & $=$ heating zone & \\
\hline$W$ & $=$ wall & \\
\hline$<\mathrm{S}$ & uperscript > & \\
\hline- & $=$ mean value & \\
\hline
\end{tabular}

\section{Literature cited}

1) Aihara, T. : J. Heat Transfer, 29, 903 (1963)

2) Anderson, R. and A. Bejan : Int. J. Heat Mass Transfer, 24, 1611 (1981)

3) Aung, W., L. S. Fletcher and V. Sernas : ibid., 15, 2293 (1972)

4) Bar-Cohen, A. and W. M. Rohsenow : J. Heat Transfer, 106, 116 (1984)
5) Bodoia, J. R. and J. F. Osterle : ibid., 84, 40 (1962)

6) Burch, T., T. Rhodes and S. Acharya : Int. J. Heat Mass Transfer, 28, 1173 (1985)

7) Currie, I. G. and W. A. Newman : Heat Transfer 1970, Elsevier Pub., 4, NC 2.7 (1970)

8) Elenbass, W. : Physica, Holland, 9, 1 (1942)

9) Goldstein, R. J. and D. G. Briggs : J. Heat Transfer, 30, 490 (1964)

10) Hardwick, N. E. and E. K. Levy : ibid., 95, 289 (1973)

11) Hasegawa, S. and M. Morisue : Preprints of the Meeting of JSME. at Miyazaki, 33 (1960)

12) Kettleborough, C. F. : Int. J. Heat Mass Transfer, 15, 883 (1972)

13) Kishinami, K. and N. Seki : J. Heat Transfer, 105, 759 (1983)

14) Kobayashi, A. and Y. Fujimoto : ibid., 20, 233 (1954)

15) Miyatake, O. and T. Fujii : Kagaku Kōgaku, 36, 405 (1972)

16) idem : ibid., 36, 859 (1972)

17) idem : ibid., 37, 491 (1973)

18) idem : ibid., 37, 852 (1973)

19) Nakamura, H. et al. : Preprints of the 42th National Meeting of JSME., No.120, 5 (1964)

20) Nakamura, H., Y. Asako and T. Naitou : Numerical Heat Transfer, 5, 95 (1982)

21) Sparrow, E. M. and J. L. Gregg : J. Heat Transfer, 78, 435 (1956)

22) Sparrow, E. M., G. M. Chrysler and L. F. Azevedo: ibid., 106, 325 (1984)

23) Wirtz, R. A. and R. T. Stutzman : ibid., 104, 501 (1982)

24) Yang, K. T., J. L. Novotny and Y. S. Cheng : Int. J. Heat Mass Transfer, 15, 1097 (1972)

\title{
Natural Convective Heat Transfer between Vertical Parallel Plates with Symmetric and Asymmetric Heating
}

\author{
Tamotsu Hanzawa, Hideki Ishihara, Kuniaki Sekiguchi* \\ Takahiko Fujii ${ }^{* *}$, Yasuo Suzuki ${ }^{* * *}$ and Kunio Kato \\ Dept. of Chem. Eng., Gunma Univ., Kiryu 376
}

\begin{abstract}
Key Words : Heat Transfer, Vertical Parallel Plates, Natural Convection, Laminar Flow, Heat Transfer Coefficient, Symmetric Heating, Asymmetric Heating, Electronic Device Cooling
\end{abstract}

To analyze the heat transfer phenomenon in electronic circuit plates, natural convective heat transfer between two vertical parallel plates, with symmetric or asymmetric uniformly heated wall, was investigated experimentally in the range of high Grashof number $\left(G r=10^{3}-10^{7}\right)$. 
The local heat transfer coefficient was strongly affected by the axial distance of the plate in the case where distance and temperature difference between plates were small. Average Nusselt number was affected by Grashof number, distance and temperature difference between the plates. An empirical equation for average Nusselt number in the two vertical parallel plates was obtained.

* Hitachi Condenser Co., Ltd.

** Kurashiki Kako Co., Ltd.

*** Hitachi Process Computer Engineering Co., Ltd.

\section{ポリエチレン系粒子に対するウシ $\mathrm{T}$ 細胞の粘着速度 ${ }^{\dagger}$}

\section{古崎新太郎・鈴田哲也*}

\section{東京大学工学部 化学工学科}

各種の血球を，その機能を失うことなく迅速に分離す ることは，診断あるいは治療の分野で望まれており各方 面で研究が進められている ${ }^{10)}$. 中でも, リンパ球の B 細 胞と T細胞とを分離することは臨床的に有用であり, 従 来からシリコン化ガラス, ナイロンなどの素材を用いて 分雚が行われている. これらの素材ではB 細胞を素材に 粘着させて血浆中に残留する $\mathrm{T}$ 細胞を採取するのである が, 乙の場合, 得られる $\mathrm{T}$ 細胞の変形を抑制し機能の変 化をできるだけ小さくする必要がある．乙の目的のため に2ーヒドロキシェチルメタクリレート（HEMA）の重合 体 (PHEMA) を粘着材表面にコーティングした材料が 開発されている6,8).

本研究は，機能の低下を起こさずに $\mathrm{T}$ 細胞を分離する 操作の基礎的検討事項として, $\mathrm{T}$ 細胞の分霍材料への可 逆的拉よび不可逆的粘着速度をポリエチレン粒子(PE)なら びにそれに HEMAをグラフト結合させた粒子（PEH）に について求めたものである.

\section{実験方法}

粘着材粒子は東燃石油化学製ポリエチレン $\mathrm{Y} 6071^{\circledR}$ お よび，乙れに電子線グラフト重合法により HEMA を導 入したものを用いた．後者のグラフト率（グラフト前の 乾燥重量を基準とした重量増加率）は18\%であった。こ れらの物性值はTable 1亿記した。

粘着される試料にはウシリンパ球 T細胞を用いた。ま

† 1986年 2 月 19 日受理 ; 化学工学協会第19回秋季大会 （名古屋, 1985年10月）にて発表

\# $=113$ 文京区本郷 7-3-1

* 住友化学 (株) 愛媛研究所
ず, ウシ全血に抗凝固剤としてクエン酸ナトリウム $5 \mathrm{~kg} /$ $\mathrm{m}^{3}$ を加え,乙れに等量の生理的りン酸塩緩衡液 (PBS)

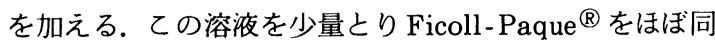
量加えて遠心分離する. 分蓶後の中間層からリンパ球お よび単球を含む層を採取するが，精製のために同様の操 作をさらに 2 回繰り返した。このとき, Trypan blue で 染色して測定した細胞の生存率は 90 〜 95\%であった. 次 いでナイロン織維を用いて単球，B細胞および混入血小 板を除去した。得られた細胞の懸濁液はPBSで目的の濃 度に稀釈して使用した。試料調整の詳細については別に 示した.9 ${ }^{9}$ 上記の操作はリンパ球の取扱い法として一般に 用いられているものであり ${ }^{2,3)}$, 得られた $\mathrm{T}$ 細胞の機能は 生体内に捛けるあのから大きく逸脱していないと考えら れる。

粘着速度の測定は, リンパ球の機械的損傷を防ぐため に擋拌を避けカラムを用いて行った。すすなわち，内径 0.1 $\mathrm{m}$ のシリコン処理ガラスカラムに粘着材を層高 $0.1 \mathrm{~m}$ と なるように充媜し，乙れに T 細胞を含む試料を導入して 粘着を行わせた。一定時間経過後に液を排出し，その細 胞濃度を吸光光度計 $(280 \mathrm{~nm})$ または血球計算板を用い て測定した。次いで，カラムを所定量の $1 \%$ リプシン -PBSで洗い"1), 溶出した液中の細胞濃度も同様の方法で 測定した。なお，カラムの器壁に粘着する細胞の量は無 視できることは確かめた。 また，実験開始後 $1 \mathrm{~min}$ 以内 の変形を受けていないと思われる $\mathrm{T}$ 細胞を上記脱離液で 処理すると $100 \%$ 回収できることを確かめた。

\section{実験結果の解析}

血球の粘着速度については, ポリアミン系の高分子を 